\title{
Commentary: Innovation in pediatrics: Aortic valve ring
}

\author{
Carl L. Backer, MD
}

\author{
From the Division of Cardiovascular-Thoracic Surgery, Ann \& Robert H. Lurie Children's Hospital of Chicago, \\ Chicago, Ill; and Department of Surgery, Northwestern University Feinberg School of Medicine, Chicago, Ill. \\ Disclosures: Author has nothing to disclose with regard to commercial support. \\ Received for publication July 11, 2019; accepted for publication July 12, 2019; available ahead of print Aug 27, \\ 2019. \\ Address for reprints: Carl L. Backer, MD, Division of Cardiovascular-Thoracic Surgery, Ann \& Robert H. Lurie \\ Children's Hospital of Chicago, 225 E Chicago Ave, mc 22, Chicago, IL 60611 (E-mail: cbacker@ \\ luriechildrens.org). \\ J Thorac Cardiovasc Surg 2020;159:e139 \\ $0022-5223 / \$ 36.00$ \\ Copyright (C) 2019 by The American Association for Thoracic Surgery \\ https://doi.org/10.1016/j.jtcvs.2019.07.043
}

It is rare in the current era to review an operation that is truly a novel procedure for pediatric patients. The case report from Wolsky and colleagues ${ }^{1}$ is to my knowledge the first case report of a pediatric patient with bicuspid aortic valve and severe aortic valve insufficiency having a quite successful internal aortic ring annuloplasty. The bicuspid annuloplasty ring has been previously reported in adult patients but it appears that it can also be used in appropriately selected pediatric patients. The patient in this report was 12 years old and weighed $58.7 \mathrm{~kg}$. The $19-\mathrm{mm}$ bicuspid aortic ring restored "normal" geometry of the aortic valve and brought the native leaflets into better coaptation. The authors also predict this will prevent future annular dilatation. In this case the regurgitant fraction according to magnetic resonance imaging was decreased from $40 \%$ to $12 \%$.

An important distinction to be noted I believe is that the $19-\mathrm{mm}$ aortic ring behaves much differently than a $19-\mathrm{mm}$ aortic valve. The flow characteristics through this ring are much better than the flow characteristics through a rigid 19-mm orifice of a bioprosthetic or mechanical aortic valve. In fact the authors suggest and the data from adult implants support the 19-mm ring as providing an adequate hemodynamic orifice for most patients. The technical aspects of the operation appear straightforward and are well described in this report. However, appropriate selection of patients for this procedure is critical. The patients must be properly selected with a bicuspid aortic valve that is amenable to this technique. The authors have described these criteria.

The congenital heart surgery community I am sure is quite interested in the long-term follow-up of this patient. The patient has now been followed for 1 year and continues to have a good result. The real question will be what the

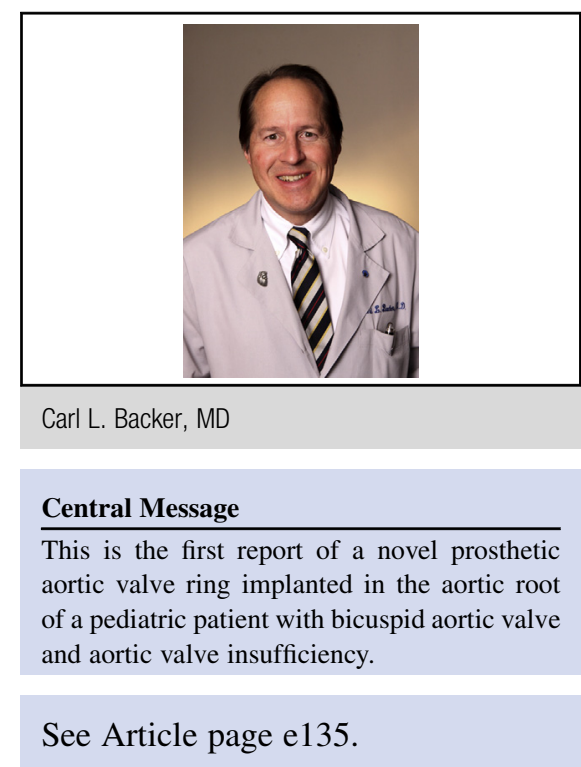

gradient is after the patient has achieved full growth. The question of durability of the aortic ring will only be answered after many years have passed.

One wonders if placement of aortic rings will ever become as common as placement of mitral rings. Certainly it is a step forward to have this technique in the surgical armamentarium for pediatric patients with bicuspid aortic valve. As this technique is used and the patients are followed I would predict that the annuloplasty ring will be gradually altered much as mitral rings were altered over the years to improve the outcomes with this surgical approach. One difference, however, is that this aortic ring was developed using advanced 3-D models of the aortic root and outflow tract. Mitral rings were originally introduced more than 30 years ago before advanced 3-D imaging and have been modified as our understanding of the mitral annulus has evolved with the use of advanced imaging. Congratulations to the authors-we eagerly anticipate the long-term follow-up of this new innovative technology.

\section{Reference}

1. Wolsky RM, Rankin JS, Meza JM, Hughes GC, Turek JW. Geometric ring annuloplasty for bicuspid aortic valve repair in a child. J Thorac Cardiovasc Surg. 2020;159:e135-7. 